\title{
Peculado y reparación material en Ecuador
}

\section{Embezzlement and material reparation in Ecuador}

1 Ana Lucía Ponce Andrade Instituto de Altos Estudios Nacionales, Quito, Ecuador ana.ponce@iaen.edu.ec

2 Richard Ítalo Villagómez Cabezas

Universidad Andina Simón Bolívar, Quito, Ecuador richard.villagomez@uasb.edu.ec

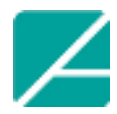

Ciencia Digital

ALFA PUBLICACIONES, es una Revista Multidisciplinar, Trimestral, que se publicará en soporte electrónico tiene como misión contribuir a la formación de profesionales competentes con visión humanística y crítica que sean capaces de exponer sus resultados investigativos y científicos en la misma medida que se promueva mediante su intervención cambios positivos en la sociedad. https://alfapublicaciones.com

La revista es editada por la Editorial Ciencia Digital (Editorial de prestigio registrada en la Cámara Ecuatoriana de Libro con No de Afiliación 663) www.celibro.org.ec

Esta revista está protegida bajo una licencia Creative Commons Attribution Non Commercial No Derivatives 4.0 International. Copia de la licencia: http://creativecommons.org/licenses/by-nc-nd/4.0/ 


\section{Palabras}

claves:

administración

pública, derecho

penal, fidelidad

de

cumplimiento, reparación,

derechos

fundamentales.

\section{Keywords:}

public

administration, criminal law, fidelity compliance, repair, fundamental rights.

\section{Resumen}

El ciclo evolutivo de la noción y fundamento de la lesividad en el delito de peculado ha variado en el tiempo, considerándose esencialmente que afectaba el erario público; luego, esto osciló hacia la fidelidad de cumplimiento de las funciones de los servidores públicos y dignatarios. Este trabajo buscó integrar desde las perspectivas jurídica y administrativa una visión holística sobre el delito de peculado, el reproche, sus efectos nocivos y la dañosidad como fundamento sustancial de la reparación integral. Para este fin, a partir de la descripción típica se analizó la participación del intraneus y extranesus a partir de la condición de comunicabilidad impuesta por el artículo 233 de la Constitución de la República del Ecuador y la dañosidad de esta conducta que no siempre es patrimonial y se manifiesta en la afectación que representa sobre la planificación, el presupuesto institucional, el cumplimiento de sus fines y la realización de derechos de la población. La reparación material entonces resulta un punto controvertido a ser probada en juicio al igual que delito y responsabilidad. Luego, la efectividad de la ejecución de la reparación material y su intensidad ya sea aritmética o geométrica.

\section{Abstract}

The evolutionary theory of the notion and foundation of harmfulness in embezzlement has varied over time, initially affecting the treasury; later, this oscillated to the fidelity of fulfillment of the functions of public servants and dignitaries. The purpose of this work, from the legal and administrative perspectives, is to integrate a holistic vision on the crime of embezzlement, reproach, its harmful effects and damage as a substantial basis for comprehensive reparation. Therefore, the participation of the intraneus and extraneous was analyzed based on the typical description and the communicability condition imposed by the article 233 of the Constitution of the Republic of Ecuador. The damage of this behavior is not always patrimonial, having an impact on the planning, the institutional budget, the fulfillment of its purposes and the realization of the population's rights. Thus, material reparation must be proven in court as well as crime, responsibility and effectiveness of the execution of material reparation and its intensity, whether arithmetic or geometric. 


\section{Introducción}

Desde un ejercicio argumental cimentado en la Filosofía se ha expresado que el Derecho Penal legitima su razón de ser a partir de la lesividad (dañosidad), entendida como la necesidad de intervención punitiva basada en la tutela de bienes jurídicos relevantes (Mir Puig, 2006). De este modo, solo cuando se cumple con esta justificación de tutela, el uso del iuspuniendi es legítimo Muñoz (2007) y varía su intensidad conforme el (dis) valor de tales bienes jurídicos y la dañosidad que representa su vulneración. La presente obra parte de los trabajos: (a) El delito de Peculado en el Código Orgánico Integral Penal (2014); y, (b) Villagómez Ponce (2017) que han servido de insumo para el estudio del fenómeno en la actualidad.

Ahora, considerándose lo expresado por Hegel (1966) quien analizó la subsistencia de las materias independientes, donde fuerza (entendimiento) y determinación se obtienen a partir de la fusión analítica de diversas ciencias puesto que no tienen ninguna sustancia propia que las sostenga y mantenga" (p. 88); por ello, a decir de Ponce (2020) "el sustento del holismo radica en la proposición de que el universo es una totalidad integrada, conectada, que a diferencia de los métodos reduccionistas, enfatiza en un concepto expandido de la ciencia y del potencial humano" (p. 22), siendo conforme expresa Wompner (2008) un paradigma metodológico y epistemológico que permite analizar los fenómenos desde una perspectiva integral y conectada bajo el concepto expandido de la ciencia y del potencial humano. En este sentido, este trabajo buscó un análisis expandido del peculado, su ocurrencia y consecuencia desde varias perspectivas: jurídica y administrativa.

En el delito de peculado, la lesividad en su decurso evolutivo ha tenido tres momentos Donna (2008): Primero, se centró en la tutela de la res pública, siendo por tanto un delito de resultado al producirse afectación presupuestaria o patrimonial estatal que debe probarse en juicio (Creus, 1998). Más adelante, el peculado buscó la fidelidad de cumplimiento de deberes por el funcionario, dignatario, servidor público, encargado de la custodia de bienes del Estado Villagómez \& Ponce (2015), sin que sea necesaria la afectación al erario nacional (seccional) por ser un delito de función en que se reprocha la infracción normativa en que incurre el agente García (2011) al transgredir el margen de sus funciones competenciales fijados por el marco normativo.

En la actualidad, dada la complejidad del fenómeno delictivo, las dos posiciones doctrinales anteriores son insuficientes para explicar la dinámica delictual Villagómez \&Ponce (2015); Villagómez \& Ponce (2017), el iter criminis en el que incluso concurren varios delitos (concurso real/ideal) por lo que al definirse la tipicidad del peculado y su dañosidad se suscitó la mixtura de las dos corrientes anteriores, para expresar que bien puede afectarse el erario público y la fidelidad de cumplimiento de los deberes de funcionarios, servidores públicos o dignatario, sin que éstos sean elementos concurrentes 
en la probanza. Este posicionamiento doctrinal, ha sido también recogido en el marco normativo vigente y desarrollado mediante diversos fallos indicativos de la jurisdicción ordinaria, sin que exista jurisprudencia obligatoria dictada por el Pleno de la Corte Nacional de Justicia.

El delito de peculado se mantiene como conducta punible en el Código Orgánico Integral Penal [COIP] (2014) dentro de la Sección Tercera, que trata de los delitos contra la eficiencia de la administración pública. Conforme este criterio clasificador se trata de un injusto penal que reprocha al servidor, funcionario público o dignatario el cumplimiento de sus deberes previstos en el ordenamiento jurídico, de forma que la noción de lesividad no se centra exclusivamente en la afectación presupuestaria o patrimonial. Del mismo modo, se mantiene la condición de comunicabilidad prevista en el artículo 233 de la Constitución de la República del Ecuador [CRE] (2008) por la que el delito también es reprochable a terceros, siempre con la participación básica (obligatoria) del sujeto activo calificado, suscitándose el delito propio e impropio de peculado que abarca ampliamente la participación penal.

Bajo esta perspectiva típica aplicada al proceso penal, corresponde en el delito de peculado probar los elementos constitutivos de la conducta, luego la antijuridicidad y culpabilidad para el juicio de reproche al sujeto activo calificado en relación con la función de servidor público y/o dignatario que luego se extiende a terceros. Satisfecho el juicio de tipicidad para la configuración del delito y el juicio de reproche para la atribución de culpa, corresponde también un debate específico sobre la reparación integral que comprende lo material e inmaterial (restitución, garantía de no repetición, medidas de satisfacción, rehabilitación).

\section{Metodología}

En este trabajo se utilizó para la recolección y procesamiento de los datos un enfoque de cualitativo, explicativo, orientado a describir y analizar la complejidad del fenómeno delictivo del peculado y su dañosidad. Para la recolección de la información se utilizó el análisis documental como un esquema de producción teórica Ponce (2020) basado en un proceso dialógico (inductivo-deductivo) Rule \& John (2015), que permitió la generalización analítica a partir de las relaciones existentes entre teoría, investigación y práctica. En el desarrollo del proceso dialógico, se aglutinaron tres ejes de discusión en relación con el objetivo de la investigación: (a) el delito de peculado, (b) el reproche al intraneus-extraneus; y, (c) la dañosidad ocasionada como fundamento sustancial de la reparación integral. Logrando, integrar desde las perspectivas jurídica y administrativa una visión holística sobre el delito de peculado, el reproche, sus efectos nocivos y la dañosidad como fundamento sustancial de la reparación integral. 
La investigación, optó por la perspectiva filosófica construccionista para la creación del conocimiento por el dominio de múltiples relaciones Anderson (1997), demostrando que la verdad se construye socialmente.

\section{Resultados y Discusión}

Inicialmente se ha de considerar que desde la perspectiva de la Filosofía del Derecho que legitima la intervención del derecho penal, la delimitación del objeto de protección jurídica constituye base y límite del derecho penal ya sea que se lo mire desde la complementariedad de la ciencias sociales y el Derecho Penal que integran el sistema social; luego, el objeto del interés del Derecho Penal circunscrito a las conductas socialmente dañinas, la relación víctima-victimario y ahora su enfoque encaminado hacia la reparación integral y el análisis sobre los efectos dañosos en la sociedad; y, finalmente, la conexión que debe existir entre la realidad social y la creación de normas por el legislativo (Hassemer, 1984). De este modo, se busca un sistema coherente e integrado para el tratamiento del delito, el delincuente, la víctima y la reparación dentro del modelo de Estado Constitucional de derechos y justicia.

Pese al amplio espectro de la reparación integral previsto a nivel constitucional (artículo $78 \mathrm{CRE}$ ) y legal (artículo $78 \mathrm{COIP}$, material e inmaterial), parecería que el objeto de la probanza, debate y decisión judicial se centra casi exclusivamente en lo material dado que la ocurrencia del peculado puede provocar con mayor o menor intensidad afectación patrimonial o presupuestaria y el (in) cumplimiento de los fines institucionales que tienen por propósito la satisfacción de derechos de la población. De modo que, la fijación del quantum de la reparación material en sentencia con caracteres de res iudicata debería facilitar su cobro a los condenados; sin embargo, la ejecución penal, aunque se ha simplificado con la aplicación supletoria de las reglas del Código Orgánico General de Procesos (2017), no siempre representa efectividad en la recaudación de tales valores para el cumplimiento de los fines institucionales inicialmente afectados por la ocurrencia del delito.

Así, la determinación del monto de la reparación material, se incluye en el debate dentro del método reconstructivo o historiográfico Jauchen (2009), esto luego de la tipicidad y culpabilidad (artículo 453 COIP), constituye uno de los aspectos más trascendentes en el ámbito probatorio Restrepo et al. (2004) y del debate en juicio, puesto que la acusación fiscal debe satisfacer este requerimiento en que si bien existe libertad probatoria (numerus apertus) la clave de tal discusión radica en la pertinencia o relevancia de la prueba ya sea testimonial, pericial y/o documental que radica en la vinculación de su contenido con el objeto del debate procesal Martín (2016), prefiriéndose la prueba directa por sobre la indiciaria (Álvarez, 2008). 
De ello depende la eficacia de la prueba y la concreción de la pretensión punitiva Acuña (2017) dado que pertinencia, conducencia y suficiencia se orientan a la eficiencia, desterrándose la duda dentro de un estándar valoratorio respetuoso del debido proceso (Aguilera, 2013). En este sentido, un perito aporta en el examen de una cuestión debatible, ya sea comunicando principios generales fundados en la experiencia, hechos que solo se pueden percibir a través de especiales conocimientos; y, a través de conclusiones obtenidas científicamente (Roxin \& Schünemann, 2019). En tanto que, el testigo experto declara sobre hechos pasados para cuya percepción fue necesario un conocimiento especial (Roxin \& Schünemann, 2019).

El artículo 622. 6 COIP dentro de los requisitos de la sentencia condenatoria obliga al órgano jurisdiccional fijar el quantum de la reparación material sobre la base de prueba completa es decir una vez resuelta la existencia del delito y la responsabilidad del procesado Alliaud (2018), lo que constituye una nueva forma de punición que obliga a reorientar las finalidades de la pena Sueiro (2016) ora en el debate en el ámbito académico Binder (2018) y su adecuación al contenido del artículo 201 de la Constitución de la República del Ecuador. No obstante, en la decisión judicial la dificultad interpretativa radica en la carencia de fórmula de cálculo prevista en la ley, de lo cual existe un amplio margen de interpretación judicial que se sustenta en parámetros disimiles que conspiran en contra de la motivación de las decisiones judiciales prevista en el artículo 76.7.1 CRE y la seguridad jurídica garantizada en al artículo 82 Ibídem. En este escenario variopinto, en prescindencia del principio de legalidad, los decidores toman para fijar tal requisito de la condena: (a) El criterio decimonónico de daño emergente y lucro cesante que es propio de los procesos indemnizatorios de naturaleza no penal, lo cual representa interpretación extensiva de la norma, (b) Mediante "supletoriedad" (interpretación extensiva) se aplica la fórmula de pago dada por el Código de Trabajo que incluye: daño (temporal/permanente) remuneración versus expectativa de vida; y, (c) A través de analogía (in bonam/malam partem) se toman casos de Corte IDH en los que se ha declarado responsabilidad internacional de los Estados y se los aplica en jurisdicción ordinaria (nacional) sin distinción sobre la tipicidad (culpa/dolo) y de la participación penal.

Estas formas de interpretación judicial son contrarias a lo que dispone el artículo 13 COIP que establece que en materia penal se ha de estar a la interpretación restrictiva, prohibiéndose la extensiva, la analogía y sobre todo se enfatiza en que los jueces en calidad de garantes de derechos (artículo 424 CRE) realicen interpretación jerárquica e integrada al momento de decidir los casos concretos y el quantum de la reparación material. 
La comunicabilidad de circunstancias en el delito de peculado (propio/impropio) dada por el artículo 233 CRE también tiene trascendencia al fijarse de modo individualizado la reparación material, distinguiéndose entre intraneus y extraneus (autoría/complicidad).

La individualización de la responsabilidad es parte esencial de la discusión penal en concurrencia de varios acusados. En el delito de peculado, en calidad de intraneus bien puede existir varios coacusados siendo necesario precisar si pestos son autores y/o cómplices (artículos 42 y 43 COIP) a partir de la distinción de actos ejecutados ya sean principales o secundarios para la consumación de la conducta. En tanto que, no se excluye la posibilidad de participación de extraneus. No obstante, tanto la doctrina como la jurisprudencia al tratar la situación del extraneus en el peculado tienen criterio controvertido al momento de definirse la participación de éste y su encuadre en la calidad de autor o cómplice. Esta divergencia sobre la participación luego es significativa al fijarse la medida de la pena privativa de libertad y la obligación de pago de la fracción correspondiente de la reparación material conforme el artículo 628.1 COIP. De lo dicho se tiene que, de acuerdo con la participación (autoría/complicidad) intraneus/extraneus, corresponde la determinación del quantum de la reparación material.

Nótese que, para el intraneus al fijarse judicialmente en sentencia los elementos de la pena congrua, corresponde de modo distintivo, entre otros, la inhabilitación para el ejercicio de la profesión. No obstante, este componente de la pena no es extensible al extraneus quien no tiene la calidad de servidor, funcionario público o dignatario.

Los efectos dañosos del peculado no solo tienen una expresión material o económica que afectan el presupuesto de la institución estatal, sino que tal efecto se traslada a otros ámbitos que versan con las finanzas públicas y el cumplimiento de derechos ciudadanos que se planificaron cumplir a través del presupuesto que resultó dañado por la ocurrencia del delito. De modo que, la reparación material que proviene de la condena, desde una visión teleológica, debe servir para cumplir la planificación y el presupuesto de la institución. Sin embargo, el incumplimiento del pago de la reparación material por los condenados impide el cumplimiento de la planificación y el presupuesto que fue anteriormente perjudicado por la ocurrencia de la conducta punible.

La inejecución de la reparación material afecta la satisfacción de derechos que fueron planificados y presupuestados previamente. Aunque, la racionalización de las finanzas públicas permite determinar con claridad el qué y el cómo gastar a través de las reglas y principios presupuestarios Nava Escudero (2009), la ocurrencia del delito de peculado conspira en contra de la eficiencia de la administración pública y el cumplimiento y satisfacción de derechos de la población.

El Ecuador, en la CRE (2008) (artículo 1), se autodefinió como un Estado Constitucional de Derechos y Justicia, esto significa que la formulación, ejecución, evaluación y control 
de las políticas públicas y servicios públicos deben encaminarse hacia la garantía de los derechos reconocidos por la Constitución Bacigalupo (1999), la tabla 1 muestra una interpretación jerárquica e integrada del ordenamiento jurídico, tomándose: (a) la CRE (arts. 85, 241, 275, 280, 233); (b) el Código Orgánico Integral Penal (COIP 42,43,78, 278,453, 454, 622.6, 628.1); (c) el Código Orgánico de Planificación y Finanzas Públicas [COPLAFYP] (2010) arts. 9, 10, 12, 57, 70, 73, 97, 100); y, (d) Normas Técnicas de Presupuesto (2.1.4: 2.2.1; 2.2.4); ya sea que se trate del gobierno central o los Gobiernos Autónomos Descentralizados (GADs) (Villagómez \& Ponce, 2015), órganos que en definitiva buscan el cumplimiento de derechos de los ciudadanos a través de la planificación y el presupuesto para la consecución de los objetivos que se expresan en el Plan Nacional de Desarrollo.

Tabla 1

Regulación del peculado, reparación integral, planificación gubernamental y cumplimento de derechos en Ecuador

\begin{tabular}{cc}
\hline Artículos & Cuerpo Normativo \\
\hline $3,78,85,241,275,280,233$ & Constitución de la República del Ecuador \\
\hline $42,43,78,278,453,454,622.6$, & Código Orgánico Integral Penal \\
\hline $9,10,12,57,70,73,97,100$ & Código Orgánico de Planificación y Finanzas Públicas \\
\hline $2.1 .4: 2.2 .1 ; 2.2 .4$. & Normas Técnicas de Presupuesto
\end{tabular}

Nota. Adaptado de Embezzlement, Budget Affectation and Rights Infringement, in The Solidarity Economics in Ecuador, por A. Ponce, 2017, Cambridge Scholars Publishing, p. 20. Newcastle upon Tyne, England.

\section{Conclusiones}

- Una vez terminado este esfuerzo de investigación, bien puede concluirse que los planes de inversión constituyen la expresión técnica y financiera del conjunto de programas y proyectos de inversión, encaminados a la consecución de los objetivos del régimen de desarrollo. En tanto que, los planes operativos vinculan los objetivos y metas de los planes plurianuales con las metas y resultados de los programas incorporados en el presupuesto, mismos que en su primera fase de programación se definen sobre la base de los objetivos y metas determinados por la planificación, definiéndose los programas anuales y plurianuales a incorporar en el presupuesto, con la identificación de las metas de producción final de bienes y servicios, recursos humanos, materiales, físicos y financieros necesarios, y los impactos o resultados esperados por la sociedad. Desde una perspectiva financiera, el presupuesto contribuye a la estabilidad y desarrollo económico Álvarez et al. (2007), al ser un importante articulador de la política fiscal en una 
economía dolarizada vigente en Ecuador. Expresado lo anterior, desde una visión integral del derecho penal y de la administración se tiene que la ocurrencia del peculado expresa la vulneración de cumplimiento del funcionario público (intraneus) responsabilidad que por efecto del principio de comunicabilidad se hace extensible a terceros (extraneus), produciéndose no solo la afectación de la norma jurídica sino un efecto cascada que se sitúa no solo en el impacto dañoso que representa en el presupuesto institucional sino en la realización de la política fiscal y el cumplimiento de derechos que se pretende a través de éste (Villagómez \& Ponce, 2017).

- De lo expresado, el peculado como fenómeno delictivo, en un primer momento afecta la fidelidad de cumplimiento del funcionario, servidor público o dignatario, luego su efecto dañoso se amplía al presupuesto (patrimonio), los programas y proyectos planificados por el gobierno central y GADs para el cumplimiento y vigencia de derechos, conforme el artículo 3 CRE (Villagómez \& Ponce, 2015). Así, el daño inferido es multinivel, se suscita inicialmente en el ejercicio económico de la ocurrencia del delito y luego se prolonga hacia el futuro al constituirse en lastre para el cumplimiento real y efectivo de estos programas y proyectos que fueron afectados y que luego no pueden ejecutarse en tanto no se suscite ya sea: (a) el pago de la reparación material declarado en el proceso penal; o, (b) la reprogramación y asignación de fondos por la institución pública afectada que deberá volver a asignar fondos para este fin, frente al incumplimiento de la reparación material.

- En la actualidad el pago de la reparación material es parte de la sentencia condenatoria y su concreción se expresa en la ejecución penal donde ya no se discute el quantum, que quedó ya definido en la condena, por lo que el débete en este punto radica tan solo en dos opciones: ya sea, pagar o dimitir bienes. Esto no significa per se que la ejecución penal sea efectiva, dado que a esas alturas del debate procesal los bienes de los condenados pudieron ser distraídos ocasionándose otras conductas conexas (enriquecimiento privado, testaferrismo, insolvencia dolosa, etcétera) que tornan imposible la recuperación del monto económico proveniente de la afectación provocada por la ocurrencia del delito, sino que esto se expresa en el plano administrativo en el incumplimiento de los planes de inversión y los derechos ciudadanos que se pretenden a través del presupuesto. Por lo que, finalmente la dañosidad del delito de peculado no solo se expresa en la transgresión de la norma por el servidor público sino que se multiplica provocándose un efecto ampliado (multinivel) que se expresa en la afectación presupuestaria, el incumplimiento de derechos que luego pueden o no ser asumidos por la entidad afectada, que deberá reprogramar actividades y presupuesto para incluir las que han sido afectadas, de lo cual otros derechos también serán desplazados como consecuencia de tal reprogramación, 
ocasionándose una dañosidad geométrica y no meramente aritmética.

\section{Referencias Bibliográficas}

Acuña, R. (2017). Funcionamiento y eficacia probatoria de los indicios en el proceso penal acusatorio. En Á. Ledesma, \& F. Depalma, El debido proceso penal 5 (págs. 151-178). Buenos Aires: Hammurabi s.r.1.

Aguilera, E. (2013). El estándar de la prueba y las garantías en el proceso penal. Buenos Aires: Hammurabi.

Alliaud, A. (2018). Repensando la prueba en el proceso penal adversarial. En Ledesma Angela, \& F. Depalma, El debido proceso penal 7 (págs. 147-163). Buenos Aires: Hammurabi s.r.l.

Álvarez, F. (2008). Indicios y Presunciones. Bogotá: Jurídica Bolivariana.

Álvarez, F., Corona, J., \& Díaz, A. (2007). Economía Pública Una Introducción. Barcelona: Book Print Digital.

Anderson, H. (1997). Conversación, lenguaje y posibilidades. Buenos Aires: Amorrortu.

Bacigalupo, E. (1999). Principios Constitucionales de Derecho Penal. Buenos Aires: José Depalma Editores.

Binder, A. (2018). Derecho Procesal Penal. Buenos Aires: Ad-Hoc.

Creus, C. (1998). Derecho Penal, Parte Especial (Sexta ed.). Buenos Aires: Astrea.

Código Orgánico de Planificación y Finanzas Públicas. (2010). Quito, Ecuador: Registro Oficial No 306 del 22 de octubre de 2010.

Código Orgánico General de Procesos. (2017). Quito, Ecuador: Registro Oficial Suplemento 31 de 7 de julio de 2017.

Código Orgánico Integral Penal. (2014). Quito, Ecuador: Registro Oficial Suplemento No 180 del 10 de febrero de 2014.

Constitución de la República del Ecuador. (2008). Quito, Ecuador: Registro Oficial No 449 del 20 de octubre de 2008.

Creus, C. (1998). Derecho Penal, Parte Especial (Sexta ed.). Buenos Aires: Astrea.

Donna, E. A. (2008). Derecho Penal, Parte Especial (Segunda Edición ed.). Buenos Aires: Rubinzal Culzoni Editores. 
García Martín, L. (2011 йил 11). Sobre la Necesaria Modernización del Derecho Penal. Derecho Penal Central (1), 95.

Hassemer, W. (1984). Fundamentos del Derecho Penal. Barcelona: Bosch.

Hegel, G. (1966). Fenomenología del Espíritu. México: Fondo de Cultura Económica.

Jauchen, E. (2009). Tratado de la prueba en materia penal. Buenos Aires: Rubinzal Culzoni.

Martín, A. (2016). En base a que se juzga. Notas sobre el juicio de admisibilidad de la prueba y el cambio de paradigma. En A. Ledesma, \& M. Lopardo, El debido proceso penal 1 (págs. 93-110). Buenos Aires: Hammurabi s.r.1.

Mir Puig, S. (2006). Estado, Pena y Delito. Argentina: B de f.

Muñoz, D. (2007). La Tenencia del Peligro (Primera Edición ed.). Buenos Aires: Rubinzal Culzoni Editores.

Nava Escudero, O. (2009). El Principio Presupuestario de no Afectación de los Recursos Públicos y los Ingresos Excedentes. Reforma Hacienda en la Agenda de la Reforma del Estado, 117-124.

Ponce, A. (2020). Instrumentalización de la organización para la perpetración del delito de lavado de activos por el management empresarial. Lima: Pontificia Universidad Católica de Perú.

Rule, P., \& John, V. (2015). A necessary dialogue: Theory in case study research. International Journal of Qualitative Methods, 1-11.

Restrepo, E., Sánchez, F., \& Martínez, M. (2004). ¿Impunidad o castigo? Análisis e implicaciones de la investigación penal en secuestro, terrorismo y peculado. Documentos CEDE, 1-39.

Roxin, C., \& Schünemann, B. (2019). Derecho procesal penal. Buenos Aires: Didot.

Sueiro, C. (2016). La reparación del daño en el nuevo sistema penal argentino. A raíz de su incorporación al código Penal y al nuevo Código Procesal Penal (ley 27.063). En A. Ledesma, \& M. Lopardo, El debido proceso penal 3 (págs. 30-45). Buenos Aires: Hammurabi s.r.l.

Villagómez, R., \& Ponce, A. (2015). El delito de Peculado en el Código Orgánico Integral Penal. Quito: Zona G. 
Villagómez, R., \& Ponce, A. (2017). Embezzlement, Budget Affectation and Rights Infringement. Newcastle upon Tyne: Cambridge Scholars Publishing.

Wompner, F. (2008). Inteligencia holística. La llave para una nueva era. Osorno Chile. Chile: Osorno.

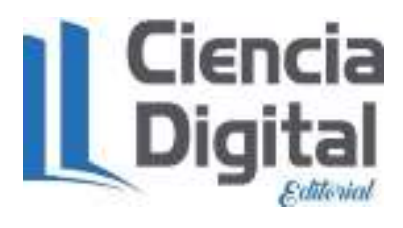


El artículo que se publica es de exclusiva responsabilidad de los autores y no necesariamente reflejan el pensamiento de la Revista Alfa Publicaciones.

\section{$\lfloor$ Ciencia}

El artículo queda en propiedad de la revista y, por tanto, su publicación parcial y/o total en otro medio tiene que ser autorizado por el director de la Revista Alfa Publicaciones.
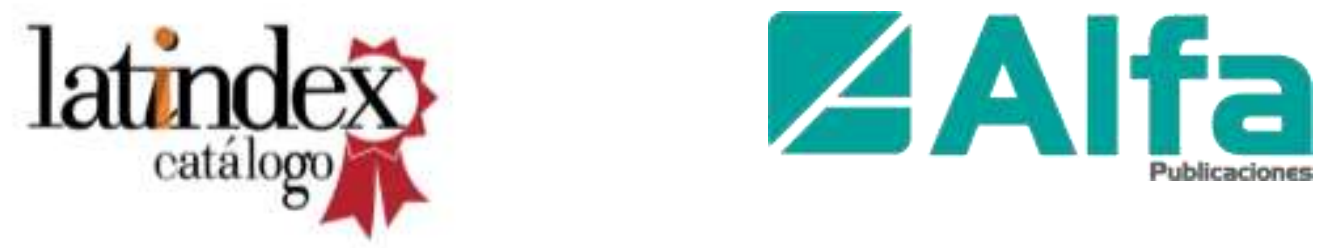

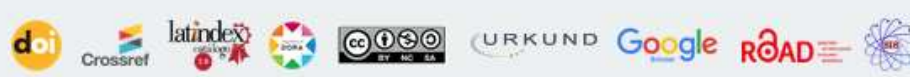
DLatinREV

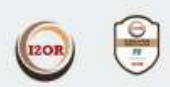

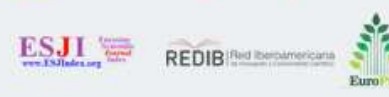
$\underbrace{}_{\text {wizdom.ai }} \bigodot_{\text {OpenAlRE }}^{\oplus}$

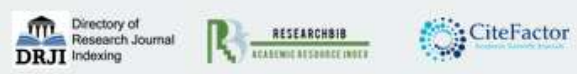

